\title{
Review of the Impact of Mechanical Harvesting and Optical Berry Sorting on Grape and Wine Composition
}

\section{David A. Hendrickson ${ }^{1}$ and Anita Oberholster ${ }^{1 *}$ \\ Cite this article: Hendrickson DA and Oberholster A. Review of the impact of mechanical harvesting and optical berry sorting on grape and wine composition. 2017. Catalyst 1:21-26.}

${ }^{1}$ Department of Viticulture and Enology, University of California, One Shields Avenue, Davis, CA 95616.

*Corresponding author (aoberholster@ucdavis.edu; tel: +1-530-754-4866; fax: +1-530-752-0382)

Manuscript submitted Aug 2016 revised Nov 2016, accepted Dec 2016

Copyright (C) 2017 by the American Society for Enology and Viticulture. All rights reserved.

doi: $10.5344 /$ catalyst.2016.16004

\section{Summary}

Aim: The need for mechanical harvesting is increasing, but there have been few new investigations into the potential impact of new-generation harvesters on fruit quality. It is thus timely to review what we know about the impact of mechanical harvesting and identify the gaps in knowledge that should be addressed. Furthermore, new technologies such as optical berry sorting may have the potential to negate the impact of mechanical harvesting on fruit quality.

\section{Key Themes:}

- This review provides a brief history regarding mechanical harvesters and concerns about their use.

- Research that evaluated the impact of harvest method on wine quality is discussed with an additional focus on the consequences of berry intactness and the influence of transport and temperature.

- An overview of optical berry sorting technology, as well as of its potential impact on wine quality, is provided.

Impact and Significance: There is a general perception that mechanically harvested grapes produce wines of lesser quality, but there is little evidence supporting that claim. Research to date indicates that the impact of mechanical harvesting on wine composition and style is less than expected. Although most studies indicate an effect of harvest type on grape and wine composition, the few that evaluated the wines sensorially found minimal impact due to harvest method. It is difficult to determine the influence of optical berry sorting because few studies have investigated this technology. In general, these studies found no large impact on wine composition and style. Only one study investigated the potential synergistic effect of using both mechanical harvesting and optical berry sorting and found that optical sorting may negate the impact of mechanical harvesting on grape composition.

Key words: grape composition, machine harvest, mechanization, optical sorting, sensory, wine composition

\section{Overview}

Given the ever-increasing cost and shortage of qualified labor and the desire to economize vineyard operations, mechanizing the harvest of grapes intended for wine production has become increasingly important over the past 50 years. Domestic labor shortages caused by World War II led to considerable pressure to develop mechanical harvesters for several agricultural crops ${ }^{1}$. Labor issues intensified again in the mid-1960s, when the United States cancelled the Bracero Program, an agreement that allowed thousands of Mexican workers into the country each year to provide agricultural labor. An ideal harvesting mechanism for grapes rapidly and efficiently selects fruit within desired parameters, while excluding materials other than grapes (MOG). Some of the new mechanical harvesters include on-board sorting systems that eliminate bits of rachis, leaves, and shoots, though these mechanisms can not exclude berries based on ripeness. 
Sorting at the winery is one option for eliminating undesirable fruit picked by mechanical harvesters. Sorting mechanically harvested fruit by hand, however, is tedious and requires tremendous resources since inspection of individual berries would be necessary to sort the already-destemmed fruit. Optical sorters, in contrast, are well suited for rapidly sorting destemmed grapes based on parameters such as berry size, color, and shape, while eliminating foreign material.

\section{Key Themes}

Mechanical harvesting. Experimentation with mechanically harvesting grapes began in California in 1953, with cutter bar harvesters that were only effective on vines trained for that purpose. The cutter bar design was replaced several years later by shake harvesters that were better suited for commercial applications $^{1}$. By 1960, designs had been submitted for patent $^{2}$, and mechanical harvesters were commercially available soon after.

Today, several companies manufacture state-ofthe-art mechanical harvesters that adapt to different trellising and canopy systems. Harvesters are classified according to the mechanism by which the fruit is removed from the vine. Most harvesters fall into two main categories: pivotal strikers or trunk shakers. Some combine both actions and may be called pivotal pulsators or striker-shakers. Pivotal striker and bow rod picking heads are canopy or foliage shakers, while trunk shakers shake the trunk as the name implies. The research studies referenced here used bow rod mechanical harvesters. The self-propelled machines straddle vineyard rows, using rapidly pulsating bowed rods to shake the vines and free berries from the rachis. Fans blow leaves and other debris off the berries as they are caught on conveyer belts and transported to onboard holding tanks or propelled into bins on adjacent tractors or trucks. One of the greatest benefits of mechanical harvesting is the relatively low cost of their operation compared to paying laborers to harvest by hand. Despite a considerable initial investment of over a quarter million dollars to purchase a new mechanical harvester, their low operating cost and high efficiency make them economically beneficial for large operations. Mechanical harvesters are also available for "rent" (for example, a contract-based harvest option), which make them accessible to smaller companies for whom purchasing a machine is cost-prohibitive. Other benefits of mechanical harvesters are their considerable harvest rate and their ability to operate around the clock. A particular advantage is that me- chanical harvesters easily cover many vineyard acres at night, when picking conditions are optimal.

Concerns associated with mechanical harvesting include: i) physical damage to the fruit resulting from the rapid shaking required to separate berries from rachis, ii) the inclusion of undesirable second crop, overripe or moldy clusters and MOG, iii) the increased risk of oxidation, enzymatic activity, and development of microbial populations in the broken, and therefore vulnerable, fruit during transport from the vineyard to winery, and iv) loss of valuable juice in the vineyard. The risk and impact of these issues are complex and depend on many factors such as value of the crop, proximity of the vineyard to the winery, and harvest conditions. The availability and cost of field labor is also relevant to the economics of mechanical harvesting.

The undifferentiating picking apparatus of mechanical harvesters incorporates under- and overripe berries into collection vessels, leading to greater tonnage per acre than hand harvesting. Conversely, handpicking can be more selective, but leaves significantly more fruit behind in the vineyard ${ }^{3}$, an issue likely exacerbated by poor visibility during night picks. Many winemakers request that the second crop not be harvested. Several factors determine which harvest method is best for a particular operation. For larger businesses that produce lower-priced wines, the efficiency and cost-effectiveness of mechanical harvesters likely outweigh concerns of picking undesirable fruit. In many instances, economic realities make mechanical harvesting the only viable option. In contrast, artisanal producers with specific stylistic goals may be willing to spend more for hand-harvesting to ensure consistent fruit quality. However, while there is a deeprooted mentality in some wine circles that mechanically harvested grapes produce wines of lesser quality, there is little evidence supporting such claims. One study that evaluated wines made with machine- and hand-harvested Chardonnay found that tasters had no significant preference between the two for both young wines and wines aged 18 months $^{3}$. Another investigated grape juice and wines from machine- and handharvested Sauvignon blanc grapes and found higher 3-mercaptohexanol (3-MH) and 3-mercaptohexyl acetate (3-MHA) in three of the five juices and wines ${ }^{4}$. If a Sauvignon blanc with tropical and fruity character is desired, high 3-MH and 3-MHA concentrations are an important component ${ }^{5}$. Musts and wines from machine-harvested Montuni grapes had higher pH's than their hand-picked alternatives ${ }^{6}$. The most likely cause was more potassium in the machine-harvested musts 
as a result of greater berry skin maceration. For the same reason, musts from machine-harvested grapes had $9 \%$ more phenolics. However, the resulting wines actually contained less phenolics than those made from hand-picked grapes. The researchers speculated that this indicated oxidation due to greater exposure to oxygen during handling. Although sensory analysis indicated significant differences among the wines due to harvest method, particularly in acidity, the differences were usually modest ${ }^{6}$. Another study using both red and white varieties (Petite Sirah, French Colombard, and Chenin blanc) found that subjects had no preference between wines made from grapes harvested by the two methods ${ }^{7}$. In a more recent study, the impact of mechanical harvesting using both standard bowrod and a new generation mechanical harvester with a Selectiv' Process on-board (a sorter removing mostly MOG) was studied using Pinot noir grapes ${ }^{8}$. Although there were phenolic and aroma compound differences among the different harvest treatments, descriptive sensory analysis found only small differences in the final wines. Only two of 18 attributes, tropical fruit aroma and hue saturation, were significantly different, indicating a very small impact on Pinot noir wine quality due to harvest method.

Rapid shaking of vines by mechanical harvesters deposits leaves, petioles, bark, canes, and trellis material in picking bins. Cultivars that are not well suited for mechanical harvesting usually contain more MOG than do easily harvested cultivars ${ }^{9,10}$. If not removed, MOG will eventually reach fermentation vessels and may alter wine composition and impart undesirable sensory characteristics. A study investigating the influence of stems, petioles, and leaves on juice and wine composition found that total phenol, flavanoid, and tannin content in wine and juice increased with the amount of MOG mixed with the harvested grapes ${ }^{11}$. Another study found that white wines made with the addition of shredded grape leaves were significantly darker than control wines by both visual assessment and spectrometric analysis. However, the same study found no significant preference among wines made from hand-harvested grapes, from mechanically harvested grapes, or from grapes to which shredded leaves had been added ${ }^{7}$.

Despite design advances that have led to gentler picking mechanisms, berry damage is still a major concern with machine-harvested grapes. The harvest process shakes fruit from the rachis and collects individual berries. This berry detachment often results in ruptured berries and juice loss ${ }^{3}$. The extent of berry damage depends on factors such as cultivar, crop conditions, type of harvester, and temperature at harvest ${ }^{1}$, 12. The structure of the cluster framework and the strength with which the grapes adhere to the vine are the main factors that determine how easily fruit is removed, and in what condition ${ }^{13}$. Varieties that produce firm berries with tough skin are suited for mechanical harvesting, while more delicate varieties will experience greater damage and juice loss. In practice, Cabernet Sauvignon, Gewürztraminer, Rubired, and Palomino are well suited for mechanical harvesting, while Grenache, Zinfandel, Emerald Riesling, Muscat Canelli, and Burger are poorly suited ${ }^{12-14}$. However, this observation is based on outdated studies, many of which occurred 30 years or more ago using older technology. Many delicate varieties are successfully machine-harvested today, including Grenache and Zinfandel. This highlights the need for further investigations into the potential impact of mechanical harvesting on the more popular varieties in the New World wine regions.

It has been posited that mechanically harvested grapes can have better quality than hand-harvested grapes if the fruit temperature is cool and the fruit is delivered promptly to the processing facility ${ }^{14,15}$. However, numerous studies have shown that a considerable time delay between mechanical harvest and delivery of grapes to a winery for processing can lead to adverse effects including oxidation, increased enzymatic activity, browning, microbial growth, and the development of off-flavors ${ }^{7,9,13,16-18}$. Extended skin contact that may occur during transport following mechanical harvesting can increase $\mathrm{pH}$, color, total nitrogen, haze-forming proteins, and total phenol, while decreasing total acid and tartaric acid ${ }^{7,16-19}$. One study investigating the effect of delayed processing on wine quality found that increased holding times of both red and white grapes before winery processing resulted in wines that were judged inferior to control wines by panelists ${ }^{16}$.

High fruit temperatures of $35^{\circ} \mathrm{C}$ coupled with extended transport leads to rapid deterioration of mechanically harvested grapes ${ }^{1,13,20-23}$. Grapes harvested and transported under such conditions produce high levels of alcohol and acetic acid and have poor color ${ }^{22}$. The temperature of the grapes at harvest has more influence on transport storage temperature than does external air temperature. Night picking is therefore a common practice to minimize spoilage during transport. Furthermore, the addition of sulfur dioxide to machine-harvested grapes can decrease quality loss during transport ${ }^{13}, 20,21,23$. This treatment limits 
growth of unwanted yeast and bacteria populations and prevents enzymatic browning by polyphenol oxidase ${ }^{24-27}$. Sulfur dioxide additions exceeding $80 \mathrm{mg} / \mathrm{L}$ delayed alcohol accumulation and loss of soluble solids for $24 \mathrm{hr}$ in grapes held at $35^{\circ} \mathrm{C}^{21,22}$.

Optical berry sorting. Using optical sorting systems during food processing is not a recent development. Optical sorting methods were pioneered in $1965^{28}$, and visual inspection and sorting of fruits, vegetables, nuts, and meat products by machine have been commonplace since the 1980 's ${ }^{29}$. Although optical sorting of grape berries was described over 30 years ago $^{30}$, the technology at that time could only sort 64 berries/min, a rate unsuitable for commercial wine production. Only recently, as technology permitted rapid inspection of individual grapes, have optical berry sorters been used in wineries. Automated sorting by machine can theoretically inspect every berry and provide a more consistent and efficient process than traditional hand sorting. Typically, a conveyor belt or vibration table carries destemmed fruit to the optical sorter (Figure 1). The grapes fall onto a receiver and are propelled into the sorter. As the grapes cascade freely, high speed cameras record high resolution images of the fruit and other material. When the on-board computer detects a product that falls outside specified parameters, nozzles eject high-pressure blasts of air to divert the material into a reject collection vessel that removes the unwanted product. Depending on the size of the unit and settings, optical berry sorters can process between 3 and 10 tons/hr.

To establish desired parameters for berry selection, an optical sorter is "trained" by sending a sample of hand-selected acceptable grapes through the machine as it collects optical data. The sorter records the shape, color, and size characteristics of the ideal grapes and then rejects berries and objects that don't match such parameters during processing. Leaves, rachis, petioles,

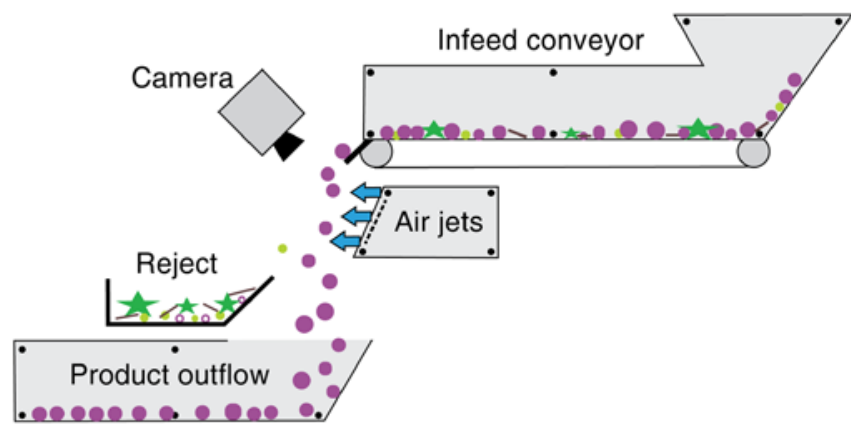

Figure 1 Schematic of an optical berry sorter. and other MOG are easily differentiated from grapes by their shape and color. By using size and color parameters, the sorters can also sort berries based on ripeness, since grape maturity correlates with berry size ${ }^{31}$ prior to berry shriveling/dehydration and with pigment accumulation ${ }^{32,33}$. Underripe berries that are inadequate in diameter or hue are removed from the processing stream. Likewise, overripe and raisined grapes are rejected based on color and shape. While an optical sorter can efficiently identify and reject over- and underripe berries, the removal of individual grapes by hand from whole clusters is a challenging, tedious, and time-consuming exercise.

Although optical berry sorters have become more common in commercial wine production, relatively few studies have investigated the effects of their use on the chemical and sensory properties of wine. In a 1978 study using early optical berry sorting technology, Muscadine grapes were sorted into four groups using absorbance parameters ${ }^{30}$. The grapes were processed and chemical analyses showed that Brix and $\mathrm{pH}$ increased with successive sorting levels, while titratable acidity decreased. In the resulting wines, $\mathrm{pH}$ and tannin levels increased and titratable acidity decreased with successive sorting levels. A sensory panel evaluated the finished wines and found that the wines made from the first and fourth sorting groups were inferior to those made from the two middle groups, which were deemed to have optimal ripeness. Although this study employed now-outdated technology, it shows that optical berry sorting can successfully segregate grapes by ripeness, and can have chemical and sensory impacts on the resulting must and wine. Wines made from sorted Chardonnay grapes had higher total phenols, $\mathrm{pH}$, and residual sugar than an unsorted control ${ }^{31}$. Sensory analysis showed that the sorted wine had greater tropical fruit aroma and sweetness. However, the wines had no significant differences in the remaining sensory attributes and the authors concluded that the wines were similar in character ${ }^{34}$. A more recent study investigated the synergistic effect of harvest method (hand or mechanical) with optical berry sorting on Pinot noir grape and wine composition ${ }^{8}$. Most differences in Pinot noir wine composition that arose from harvest method were diminished or eliminated by optical sorting. Descriptive sensory analysis detected greater tropical fruit aroma and lesser hue saturation in wines made from optically sorted grapes. The latter difference is potentially due to more intact berries, as whole-berry fermentations were employed. However, with only two significant differences among 18 
aroma, taste, and mouthfeel attributes tested, it was concluded that all treatments led to Pinot noir wines of similar character ${ }^{8}$.

\section{Significance}

Few studies have investigated the potential impact of mechanical harvesting, and even fewer have investigated the impact of optical berry sorting on grape and wine composition. The general perception is that mechanical harvesting will impact wine quality negatively, while optical berry sorting improves it. The limited number of studies available found only a small impact on grape and wine composition due to mechanical harvesting. To confirm these results, additional studies investigating the impact of mechanical harvesting on popular New World varieties are needed to determine which varieties can be harvested safely using mechanical harvesters. Similarly, two studies found that optical berry sorting had only a small impact on sensory perception of wines. These initial findings should be confirmed using other varieties. The potential impact of sorting grapes by ripeness levels also warrants further investigation to quantify the impact of optical berry sorting on wine composition and style.

\section{References and Footnotes}

1. Janick J. 1994. Horticultural Reviews. Wiley, New York.

2. Lamouria LH. 1956. Method for Harvesting Grapes and the Like. US Patent 2929184 A.

3. Clary CD, Steinhauer RE, Frisinger JE and Peffer TE. 1990. Evaluation of machine- vs. hand-harvested Chardonnay. Am J Enol Vitic 41:176-181.

4. Allen G, Herbst-Johnstone M, Girault M, Butler P, Logan G, Jouanneau S, Nicolau L and Kilmartin PA. 2011. Influence of grape-harvesting steps on varietal thiol aromas in Sauvignon blanc wines. J Agric Food Chem 59:10641-10650.

5. Lund CM, Thompson MK, Benkwitz F, Wohler MW, Triggs CM, Gardner R, Heymann H and Nicolau L. 2009. New Zealand Sauvignon blanc distinct flavor characteristics: Sensory, chemical and consumer aspects. Am J Enol Vitic 60:1-12.

6. Arfelli G, Sartini E, Bordini F, Caprara C and Pezzi F. 2010. Mechanical harvesting optimization and postharvest treatments to improve wine quality. J Int Sci Vigne Vin 44:101-115.

7. Noble AC, Ough CS and Kasimatis AN. 1975. Effect of leaf content and mechanical harvest on wine "quality." Am J Enol Vitic 26:158-163.

8. Hendrickson DA, Lerno LA, Hjelmeland AK, Ebeler SE, Heymann H, Hopfer H, Block KL, Brenneman CA and Oberholster A. 2016. Impact of mechanical harvesting and optical berry sorting on grape and wine composition. Am J Enol Vitic 67:385-397.
9. Marshall DE, Levin JH and Cargill BF. 1971. Properties of 'Concord' grapes related to JH mechanical harvesting and handling. Trans Am Soc Agric Eng 14:373-376.

10. Petrucci VE and Siegfried R. 1976. The extraneous matter in mechanically harvested wine grapes. Am J Enol Vitic 27:40-41.

11. Huang PD, Cash JN and Santerre CR. 1988. Influence of stems, petioles and leaves on the phenolic content of Concord and Aurora Blanc juice and wine. J Food Sci 53:173-175.

12. Morris JR. 1983. Effects of mechanical harvesting on the quality of small fruits and grapes. Am Soc Agric Eng 84:332-348.

13. Christensen LP, Kasimatis AN, Kissler JJ, Jensen F and Luvisi DA. 1973. Mechanical harvesting of grapes for the winery. Calif Agric Exten Bull AXT-403, University of California, Davis.

14. Johnson SS. 1977. Mechanical harvesting of wine grapes. Agricultural Economic Report 385, Economic Research Service, USDA, Washington, DC.

15. Peterson R. 1979. Most important machine picker feature may be night-time use. Calif Western States Grape Grower Dec, p. 14.

16. Ough CS, Berg HW, Coffelt RJ and Cooke GM. 1971. The effect on wine quality of simulated mechanical harvest and gondola transport of grapes. Am J Enol Vitic 22:65-70.

17. Pocock KF, Hayasaka Y, Peng Z, Williams PJ and Waters EJ. 1998. The effect of mechanical harvesting and longdistance transport on the concentration of haze-forming proteins in grape juice. Aust J Grape Wine Res 4:23-29.

18. Pocock KF and Waters EJ. 1998. The effect of mechanical harvesting and transport of grapes, and juice oxidation, on the protein stability of wines. Aust J Grape Wine Res $4: 136-139$

19. Ough CS. 1969. Substances extracted during skin contact with white musts. I. General wine composition and quality changes with contact time. Am J Enol Vitic 20:93-100.

20. Benedict RH, Morris JR, Fleming JW and McCaskill DR. 1973. Effects of temperature on quality of mechanically harvested 'Concord' grapes. Ark Farm Res 22:2.

21. Morris JR, Cawthon DL and Fleming JW. 1979. Effects of temperature and $\mathrm{SO}_{2}$ addition on quality and postharvest behavior of mechanically harvested juice grapes in Arkansas. J Amer Soc Hortic Sci 104:166.

22. Morris JR, Fleming JW, Benedict RH and McCaskill DR. 1973. Maintaining juice quality of 'Concord' grapes harvested mechanically. Ark Farm Res 22:3.

23. Morris JR, Fleming JW, Benedict RH, and McCaskill DR. 1972. Effects of sulfur dioxide on postharvest quality of mechanically harvested grapes. Ark Farm Res 21:5.

24. Vidal FD and Jayaraman A. 1983. Gaseous antimicrobial treatments of storage grain with sulfur dioxide and ammonium. US Patent 4421774 A. 20 Dec.

25. Main GL and Morris JR. 1991. Color of Riesling and Vidal wines as affected by bentonite, Cufex $\AA$, and sulfur dioxide juice treatments. Am J Enol Vitic 42:354-357. 
26. Sims CA and Morris JR. 1984. Effects of pH, sulfur dioxide, storage time, and temperature on the color and stability of red muscadine grape wine. Am J Enol Vitic 35:35-39.

27. Taylor SL, Higley NA and Bush RK. 1986. Sulfites in foods: Uses, analytical methods, residues, fate, exposure assessment, metabolism, toxicity, and hypersensitivity. Adv Food Res 30:1-76.

28. Birth GA and Norris KH. 1965. The difference meter for measuring interior quality of foods and pigments in biological tissue. Tech Bull 1341. US Dept of Agriculture, Washington, D.C.

29. Fazzari RJ, Hebel RJ and Skorina FK. 1997. High speed mass flow food sorting apparatus for optically inspecting and sorting bulk food products. US Patent $5887073 \mathrm{~A}$.

30. Carroll DE, Ballinger WE, McClure WF and Nesbitt WB. 1978. Wine quality versus ripeness of light-sorted Carlos muscadine grapes. Am J Enol Vitic 29:169-171.
31. Coombe BG and Bishop GR. 1980. Development of the grape berry. II. Changes in diameter and deformability during veraison. Aust J Agric Res 31:499-509.

32. Hrazdina G, Parsons GF and Mattick LR. 1984. Physiological and biochemical events during development and maturation of grape berries. Am J Enol Vitic 35:220-227.

33. Boss PK, Davies C and Robinson P. 1996. Analysis of the expression of anthocyanin pathway genes in developing Vitis vinifera L. cv Shiraz grape berries and the implications for pathway regulation. Plant Physiol 111:1059-1066.

34. Falconer R, Liebich B and Hart A. 2006. Automated color sorting of hand-harvested Chardonnay. Am J Enol Vitic 57:491-496. 